\title{
PROPOSIÇÃO DE AÇÕES METODOLÓGICAS PARA INSERÇÃO DAS DIMENSÕES DE EQUIDADE NAS AULAS DE MATEMÁTICA
}

\section{PROPOSITION OF METHODOLOGICAL ACTIONS FOR INSERTING EQUITY DIMENSIONS IN MATHEMATICS}

\author{
José Airton Fernandes Farias ${ }^{1}$ \\ Rodiney Marcelo Braga dos Santos ${ }^{2}$
}

\begin{abstract}
Resumo: Esta pesquisa destaca aspectos da equidade que surgem diante das dificuldades encontradas nas aulas de Matemática. As vivências e oportunidades adquiridas pelo aluno de intercâmbio são ilimitadas. Assim, optamos por apresentar o estudo preliminar de uma pesquisa de verão, realizada na Michigan StateUniversity (MSU), no estado de Michigan, EUA, que consiste no desenvolvimento de uma ferramenta, Equity Quantified In Participation (EQUIP), capaz de quantificar a participação dos alunos nas aulas de Matemática. $O$ tratamento metodológico adotado compreende uma tipologia de abordagem qualitativa e exploratória que contribuiu para o esclarecimento de questões ligadas a equidade nas aulas de Matemática, tendo por base a observação participante a partir de um intercâmbio internacional.Contudo, contribuiu para a elaboração de uma proposição de ações metodológicas através das dimensões de equidade nas aulas de Matemática, que tem o intuito de auxiliar nas pesquisas e práticas matemáticas.
\end{abstract}

Palavras-chave: Acesso; Realização; Identidade; Poder.

\begin{abstract}
This research highlights aspects of equity that arise in the face of difficulties encountered in Mathematics classes. The experiences and opportunities acquired by the exchange student are unlimited. Thus, we chose to present the preliminary study of a summer survey, conducted at Michigan State University (MSU), Michigan, USA, which consists of the development of a tool, Equity Quantified In Participation (EQUIP), able to quantify the participation in mathematics classes. The methodological approach adopted includes a typology of a qualitative and exploratory approach that contributed to the clarification of issues related to equity in Mathematics classes, based on participant observation from an international exchange.However, he contributed to the elaboration of a proposition of methodological actions through the dimensions of equity in Mathematics classes, which aims to assist in mathematical research and practice.
\end{abstract}

Keywords: Access; Achievement; Identity; Power.

\section{Introdução}

(Re)criar um modelo educativo que o professor deva seguir tem muito a ver com o que o próprio entende como ensino de qualidade. Para refletirmos sobre o caráter

\footnotetext{
${ }^{1}$ Licenciado em Matemática pelo Instituto Federal de Educação, Ciência e Tecnologia da Paraíba (IFPB), Campus Cajazeiras-PB. Secretária de Educação de São João do Rio do Peixe-PB, São João do Rio do Peixe, Paraíba, Brasil. E-mail: msndeairton@ hotmail.com

${ }^{2}$ Doutor em Biodiversidade e Biotecnlogia pela Universidade Federal de Roraima (UFRR). Professor efetivo do Instituto Federal de Educação, Ciência e Tecnologia de Rondônia - Campus Porto Velho (IFRO), Rondônia, Porto Velho, Brasil. E-mail: marcelllobraga@ hotmail.com
} 
humanitário do ensino, primeiramente devemos perceber quanto da vivência dos alunos pode influenciar o desenvolvimento acadêmico e profissional de um indivíduo na sociedade (MANTOAN, 2011). Dessa forma, podemos levantar alguns questionamentos, quais sejam: De que forma podemos refletir sobre equidade nas salas de aula de Matemática? De que maneira a equidade no ensino pode potencializar o processo de aprendizagem? E como o conhecimento de processos metodológicos inovadores podem influenciar em um ensino de melhor qualidade?

Hitt (2007) explica que existe equidade quando há proporcionalidade de recompensas entre indivíduos. Nesse caso, a recompensa seria a aprendizagem, pois a falta desta pode gerar uma percepção de desigualdade e injustiça. Para tanto, a necessidade de pesquisar sobre equidade, especialmente na Matemática, torna-se crucial. Conforme Mantoan (2011), ensinar a turma como um todo reflete na valorização da capacidade do aluno, levando em consideração sua identidade sociocultural.

Nossa motivação parte de uma pesquisa de verão em experiência de intercâmbio internacional, realizado na Michigan State University (MSU), no estado de Michigan, EUA, através do estudo realizado para formação de uma ferramenta, atualmente nomeada de Equity Quantified In Participation (EQUIP), ou Equidade Quantificada em Participação, capaz de medir a equidade em aulas de Matemática. Trata-se de um aplicativo que se encontra em fase de estudo e poderá realizar tais medições em tempo real, podendo ser aplicado em qualquer ambiente escolar. Essa ferramenta, depois de concluída, ajudará professores e pesquisadores, fornecendo resultados mais justos e equitativos no que diz respeito ao processo de ensino e aprendizagem da Matemática.

As vivências e oportunidades adquiridas pelo aluno de intercâmbio são ilimitadas. Assim, optou-se por apresentar o estudo preliminar de uma pesquisa de verão a partir do desenvolvimento de uma ferramenta que seja capaz de quantificar a participação dos alunos nas aulas de Matemática (EQUIP). Coube ao autor desta pesquisa estudar as dimensões capazes de serem aplicadas nas aulas de Matemática como proponentes de equidade, advindas das dificuldades encontradas na maioria das salas de aula, resultantes de fatores hereditários, hierárquicos, adquiridos ou de personalidade, partindo do pressuposto que todos aprendem de forma única e individual. Ademais, apresentar uma sugestão de proposição de ações metodológicas para a inserção das dimensões de equidade nas aulas de Matemática. 


\section{Equidade em Educação Matemática}

O termo equidade significa "Integridade quanto ao proceder, opinar, julgar; equanimidade, igualdade, imparcialidade, justiça, retidão. [...] Disposição para reconhecer imparcialmente o direito de cada um" (MICHAELIS, 2015). Diferentemente de igualdade, o conceito de equidade converge aproximadamente ao de justiça, funcionando até mesmo como um sinônimo. De fato, equidade e igualdade, tanto em sala de aula quanto fora dela, nada mais são do que duas ferramentas para desenvolvermos o senso de justiça social.

Em linhas gerais, Sun (2014) faz distinção entre tais conceitos ao afirmar que a equidade é dar a todos o que precisam para serem bem-sucedidos e a igualdade é tratar todos da mesma maneira. A noção de equidade parece menos justa do que a própria justiça, mas se olharmos por esse ângulo, isso só funcionará se realmente todos tivessem as mesmas oportunidades e começassem do mesmo ponto de partida.

Fazendo uma analogia à educação, cabe ao professor saber diferenciar na sala de aula onde se encontram as precariedades e maiores necessidades de aprendizagem, tentando assim fornecer ao ensino, de forma ponderada, um ambiente que não haja exclusões, perdas ou desvantagens. Ademais, ao darmos ênfase às discrepâncias de oportunidades em salas de aula, alguns aspectos podem ser levados em consideração: fatores socioeconômicos, políticos, geográficos, culturais, raciais, de gênero, de orientação sexual, de contexto familiar, de necessidades especiais, de idade, etc. Além destes, temos outros fatores, talvez até mais agravantes e iníquos, que são os aspectos estruturais e organizacionais implementados no sistema educacional, seja este local ou global.

No âmbito da Educação Matemática, Silva (2016) adotou como pontos de orientação em sua pesquisa sobre equidade três concepções filosóficas que nos auxiliam a entender algumas interações entre sereshumanos na sociedade,quais sejam: amaterialista, a liberalista e a pós-estruturalista.

A concepção filosófica materialistaestá baseada nas condições materiais para investigação de fenômenos e procura amparo na ciência para investigar a sociedade e seus aspectos para trabalhar na superação de desigualdades sociais (SILVA, 2016). Nessa ideologia, o homem deve possuir a sabedoria necessária para se desenvolver e interagir com a natureza e modificar as formas de interação social. 
Para Moses e Cobb (2001), a Matemática funcionou ao passar dos anos como modo de filtrar os que almejam a educação superior e melhores empregos. Assim, criando uma distribuição desigual na sociedade, fortemente relacionada às minorias de classe, gênero, raça, etnia, idioma, religião, etc. Nesse contexto, a relação do homem com o ensino da Matemática tem o poder de derrubar as barreiras construídas em volta e por esta disciplina escolar.

Ao considerar a Matemática como a "rainha das ciências", os autores afirmam que os alunos que pertencem às minorias da sociedade deveriam ter cada vez mais acesso a esta disciplina escolar, de forma a poderem conquistar postos sociais mais elevados, quebrando as barreiras acima citadas.

Diante do exposto, podemos notar certa aproximação à concepção filosófica liberalista. Segundo Silva (2016), enfatiza os direitos e liberdades básicas. Sua vertente mais igualitária sugere a correção de desvantagens econômicas e sociais, de modo a que todos possuam oportunidades iguais de sucesso. Esta vertente ressalta que todos os alunos, independente de qualquer classificação, devem possuir a mesma oportunidade de acesso ao ensino, tornando-os indivíduos com as mesmas chances que outros mais afortunados.

Pesquisas constantes em Educação Matemática endereçam, avaliam e tentam propor soluções para a questão das lacunas de equidade (BOALER, 2008; GUTIÉRREZ, 2008; LUBIENSKI, 2008; WAGER, 2014). O foco destes autores na baixa representatividade de certos grupos nas escolas, mais precisamente nas aulas de Matemática, traz a preocupação sobre quais as oportunidades de protagonismos existentes na sociedade e como elas estão sendo enquadradas em detrimento de determinadas classes.

Lubienski (2008) destaca a necessidade de intervenção na Educação Matemática, principalmente nos currículos e nas práticas de pesquisa. Wager (2014) comenta que as escolas americanas negligenciam as lacunas de equidade, assim, privilegiando crianças de cor branca e de classe média alta. Boaler (2008) acrescenta que o impacto da educação globalizada causa, em muitas escolas, uma falha na forma de pensar criticamente, de trabalhar com certos limites disciplinares e na interação produtiva entre indivíduos de diferentes culturas, salientando que uma solução seria uma melhor interação entre os alunos nas salas de aula, pois estes aprendem muito mais desta maneira do que apenas seguindo o currículo padrão das escolas. 
Em contrapartida, Gutiérrez (2008) acredita que mesmo pesquisando e endereçando os alargamentos e estreitamentos das lacunas de equidade, pouco se tem feito para erradicá-las. Embora a autora não defenda o fim destas pesquisas, aponta que elas podem disseminar o mito de que o problema das diferenças é mais técnico do que de classes, essa ideia se aproxima dos ideais pós-estruturalistas.

A concepção filosófica pós-estruturalistavisa à desconstrução da ideia de verdades absolutas, enfatizando como os seres-humanos são complexos em sua natureza. Segundo Silva (2016, p. 401), “O pós-estruturalismo recusa, repudia e desmonta a noção de fixidez de um sistema, criticando amplamente a questão das teorias homogeneizantes, racionais e dicotômicas".

Retomando a Gutiérrez (2008), as iniciativas voltadas às oportunidades não estão sendo suficientes até então, principalmente nos Estads Unidos da América (EUA). Ellington e Prime (2011) citam como exemplo os alunos afro-americanos, de classes menos favorecidas, que são desproporcionalmente representados nos cursos que fornecem as oportunidades de alto nível de desempenho. Ao corroborar com essa ideia, Andrews (2012, p. 02, tradução nossa) ressalta que “O conceito de raça está enraizado na hierarquia de poder, fazendo com que muitas pessoas de cores sejam subdominantes no contexto convencional".

Identificar os conceitos erroneamente marcados na sociedade e combatê-los de forma a trabalhar as oportunidades entre as minorias é sem dúvida o sentido maior da pesquisa de Silva (2016), de forma a auxiliar os grupos hereditariamente marginalizados a alcançarem uma justiça social almejada.

As concepções filosóficas adotadas por Silva (2016) nos dão a base necessária para entender os vários aspectos naturais das relações entre humanos de modo geral, o que aos poucos podemos contextualizar e aplicar no dia a dia do professor, que é o sujeito com papel de intermediário no contexto do ensino e aprendizagem. Assim, vale adentrar na especificidade das dimensões de equidade na Educação Matemática.

\section{As dimensões da equidade nas aulas de matemática propostas por Gutiérrez}

Numa tentativa aproximada de definir a equidade na Educação Matemática, Gutiérrez (2002, p. 153, tradução nossa) endereça como “a incapacidade de prever o desempenho e a participação na matemática, com base exclusivamente nas características dos alunos, como raça, classe, etnia, sexo, crenças e proficiência na 
língua dominante". Uma década depois, Gutiérrez (2012) expande o conceito de equidade, afirmando que não deveria significar apenas igualdade. De forma mais crítica, a autora relaciona o conceito com um olhar tanto ligado ao institucional quanto ao de background ${ }^{3}$ do público envolvido em suas pesquisas.

Em busca de evidências e realizando incansáveis pesquisas sobre este assunto, Gutiérrez (2012) procura abranger o termo equidade através de quatro dimensões incansavelmente presentes em suas pesquisas, delineadas como: acesso, realização, identidade e poder.

A primeira dimensão denominada de acesso se refere aos "recursos tangíveis que os alunos têm à sua disposição para o engajamento na matemática" (GUTIÉRREZ, 2012, p. 19, tradução nossa). O acesso nesse caso trata-se dos meios estruturais e pedagógicos disponibilizados para os alunos do ensino básico, como melhores profissionais da Matemática, salas de aula com recursos de tecnologia avançada, base curricular rigorosa e um ambiente de aula participativo, onde o educador consiga motivar os alunos a se engajarem na disciplina, dentro e fora da aula.

Assim, o acesso a esses recursos influencia diretamente nos resultados finais, sejam estes resultados o alcance de uma educação exemplar, seja a simples graduação e não evasão escolar. No que diz respeito ao aprendizado do aluno, quanto menos recursos, menos qualidade de aprendizagem, salvo casos raros de meritocracia, porém não trataremos disso por enquanto.

Contrapondo-se à ideia dessa primeira dimensão de Gutiérrez (2012) - em certo ponto - podemos citar Franco et al., (2007, p. 282), que enfatiza

[...] a pura e simples existência dos recursos escolares não é condição suficiente para que os recursos façam diferença: faz-se necessário que eles sejam efetivamente usados de modo coerente no âmbito da escola.

Em termos de Brasil, é de conhecimento geral que recursos são mal distribuídos e às vezes mal administrados, sejam nas escolas, ou em qualquer repartição pública. $\mathrm{O}$ fato de recursos matemáticos existirem, mas não serem disponibilizados e utilizados efetivamente, faz com que o ideal dessa dimensão não seja tão efetivo.

Franco et al., (2007) ainda afirma que a organização e gestão do ambiente escolar são variáveis de suma importância na composição social da escola. Ademais,

\footnotetext{
${ }^{3}$ Gutiérrez (2012) trabalhou com alunos de nove escolas secundárias dos EUA que atendiam uma grande proporção de alunos latino-americanos e afro-americanos. Quatro dessas escolas foram escolhidas por seus claros ganhos e sinais de sucesso dos alunos. Outras quatro escolas foram escolhidas pelos sinais insignificantes de sucesso, com pouco ou nenhum ganho. Outra escola foi escolhida por representar o meio termo.
} 
Faria e Guimarães (2015, p. 211) discutem implicações para as políticas educacionais, ao propor uma "gestão dos recursos com foco na garantia das condições de aprendizagem", propondo uma escola de excelência com equidade, sugerindo melhor qualidade às estruturas físicas e pedagógicas das instituições, além de aumento de recursos disponíveis.

O papel do acesso aos recursos físicos e estruturais na prática educacional reflete principalmente nas oportunidades de aprendizagem, seja de forma mais sutil, seja causando grandes lacunas no sucesso acadêmico dos alunos. No entanto, Gutiérrez (2012) afirma que o foco ao acesso, por mais que seja necessário, é insuficiente. Em parte, porque gestores, professores e público em geral ainda assumem igualdade por mesmice.

Uma vez divulgada a equidade não apenas como um fator a ajudar na educação, mas sim um direito regularizado em lei, cabe a efetivação de ações norteadoras que evoquem as premissas de acesso aos recursos, tendo em vista a igualdade de oportunidades aos mais diversificados grupos.

$\mathrm{Na}$ Educação Matemática um exemplo em que esta dimensão pode ser bem trabalhada no ensino básico, seria a criação de laboratórios de Matemática, contendo uma biblioteca específica da área, com softwares matemáticos, professores especializados, bem remunerados e com foco na formação continuada.

Segundo Franco et al., (2007, p. 281), "O cenário mais positivo ocorre quando as características associadas à eqüidade intraescolar também estão associadas à eficácia escolar”. Assim, a eficácia pode ser mensurada através das práticas escolares que promovam a distribuição do conhecimento, o que possibilita o engajamento da Matemática de alto nível na educação básica. O trabalho sugerido pelo autor enfatiza a classificação de escolas através da política e práticas escolares empregadas, com o intuito de aumentar o desempenho educacional. Esta relação entre recursos e desempenho será melhor caracterizada na próxima subseção.

A segunda dimensão denominada de realização, "é medida por resultados tangíveis para os alunos em todos os níveis da matemática" (GUTIÉRRZ, 2012, p. 19, tradução nossa), envolvendo a participação de determinadas classes, padrões de interesse na área, pontuação em testes decisivos, ou mesmo numa participação mais efetiva no âmbito matemático (desde o ensino fundamental até uma carreira como profissional da Matemática ou das engenharias). 
Além do acesso às oportunidades de aprendizagem, Gutiérrez (2012) afirma que devemos levar em consideração a dimensão da realização. Temos pleno conhecimento que a Matemática está presente em vários momentos da nossa vida acadêmica e profissional, como por exemplo, no ensino regular, em olimpíadas, testes de admissão, concursos, etc. Não ter o conhecimento matemático necessário para conquistar todas essas etapas implica em não ser capaz de cumprir com alguns critérios sociais e profissionais.

É nesse momento que os profissionais da educação, em especial os da Matemática, devem refletir sobre como as oportunidades de aprendizagem estão sendo transmitidas e como estão sendo captadas pelos alunos. Será que todos estão sendo tratados iguais, ou seja, educados de maneira igual? Será que todos terão oportunidades futuras de sucesso?

De fato, não há nada que possa responder à segunda pergunta. Porém educar de maneira a garantir equidade em sala de aula passa a ser uma solução para garantir que todos tenham acesso ao mesmo nível de educação. Secada (1995) enfatiza que as barreiras ao desenvolvimento cognitivo estão diretamente conectadas ao contexto social, de crença ou simbólico em que os alunos estão inseridos. No caso do Ensino da Matemática, podemos dar ênfase às causas das inequidades como ponto de partida para aplicação do senso de justiça social. Podemos evidenciar este senso de justiça através da necessidade de superarmos as adversidades sociais do mundo contemporâneo através do "ultrapassamento de barreiras físicas, psicológicas, espaciais, temporais, culturais e, acima de tudo, garantir o acesso irrestrito de todos aos bens e às riquezas de toda sorte, entre as quais, o conhecimento" (MANTOAN, 2011, p. 60).

Detectando as barreiras de detrimento do desenvolvimento intelectual no ensino da Matemática, podemos então buscar métodos eficazes de inserção e não exclusão do processo de ensino e aprendizagem, tanto individualmente quanto coletivamente. Destacando ações que possam ter iniciado o processo de injustiça, de certa forma podemos tentar compensar os que não se enquadram em certos grupos dominantes.

A terceira dimensão se refere à de identidade. Gutiérrez (2012) destaca que a maioria dos educadores matemáticos relata encontrar nas escolas problemas de identidade cultural, partindo do ponto de vista que existem grupos historicamente desfavorecidos que experimentam gigantesca discriminação nas escolas.

Essa dimensão da equidade é a que provavelmente mais se alarga para fora do contexto educacional, sendo que nossa sociedade, desde o seu princípio de formação 
separa certas classes de indivíduos em grupos, seja por raça, sexo, etc. Outros tipos de separação levam em consideração fatores históricos, culturais e religiosos, e vale observar que o preconceito envolvendo a identidade própria de cada ser ao invés de ser extinto do âmbito escolar, parece apenas se perpetuar, seja qualquer nível ou âmbito que a escola esteja inserida.

Segundo Gutiérrez (2012), os problemas de identidade na Educação Matemática podem incluir o pouco conhecimento matemático como uma prática cultural, de forma que possa retardar a evolução dos alunos na área. Ela sugere que os educadores matemáticos possam trabalhar e valorizar ainda mais as raízes de seus alunos, resultando na quebra da barreira da contextualização da matemática na realidade dos alunos. A autora ainda afirma que essa esfera de identidade se assemelha ao Programa Etnomatemática de Ubiratan D’Ambrosio (D'AMBROSIO, 2005, 2006).

O Programa Etnomatemática tem como objetivo encorajar as "reflexões mais amplas sobre a natureza do pensamento matemático, do ponto de vista cognitivo, histórico, social, pedagógico" (D'AMBROSIO, 2005, p. 17). O próprio autor denomina sua corrente como Programa de Pesquisa, pois se trata de uma constante procura do entendimento entre o saber e o fazer matemático.

Assim como as dimensões de equidade, D’Ambrosio (2005) divide o Programa Etnomatemática em dimensões, sendo elas: a conceitual, que trata das implicações pedagógicas desta na história e filosofia da Matemática; a histórica, que faz um paralelo entre as ideias matemáticas e os fatos históricos relacionados com as ciências; a cognitiva, que lida com as características singulares da espécie humana, como comparação, classificação, medição, explicação, generalização, inferência e avaliação no âmbito do pensamento matemático; a epistemológica, que aborda os sistemas de conhecimento e procura responder questões filosóficas fundamentais; a política, que evidencia questões históricas de dominação, de conquista, de poder e assimilação de cultura e, por último, a educacional, que explicita o fortalecimento da Educação Matemática pela etnomatemática, privilegiando o raciocínio qualitativo de forma crítica, a ser implementada nos sistemas educacionais.

A dimensão identidade não se relaciona apenas com o caráter histórico e sociocultural, mas também faz um balanço das relações entre o ser e as outras pessoas que o rodeiam. À guisa de exemplificação, Gutiérrez (2012) usa uma analogia a que ela chama "metáfora janela/espelho", em que os alunos precisam enxergar eles próprios nos 
currículos escolares (o que lembra um espelho), e capazes de se reconhecerem em um contexto mais global (remetendo-se a uma janela).

Além do mais, "os alunos deverão ser capazes de se tornarem pessoas melhores em seus próprios olhos, não apenas aos olhos dos outros" (GUTIÉRREZ, 2012, p. 19, tradução nossa). Todavia, D’Ambrosio (2005) ressaltaque a proposta não é substituir os modelos tradicionais de Ensino da Matemática pelas práticas acima sugeridas, e sim saber fazer os professores reconhecerem a etnomatemática em sua prática docente e os alunos a reconhecerem, neles próprios, o balanço entre serem espelhos ou janelas.

Supondo que na prática os alunos consigam alcançar um alto nível da Matemática, obtendo resultados acadêmicos excelentes e oportunidade de ser a melhor versão deles próprios, isso ainda não seria o suficiente para assegurarem uma carreira sólida na área da Matemática, ou mesmo em se tratando do seu alcance social e profissional. Por esse motivo mais uma dimensão é levada em consideração, qual seja o poder.

A dimensão de poder é mensurada por Gutiérrez (2012) através de quatro níveis de atuação:

a) voz na sala de aula. Quem detiver o poder de voz ativa na sala, também terá o poder de decidir o rumo da aprendizagem. Alguns exemplos seriam os estudiosos que decidem o currículo matemático, ou o professor que é capaz de controlar o nível de aprendizagem em sala, ou mesmo aquele aluno que gosta de participar mais que outros e por consequência acaba chamando mais a atenção do professor, deixando os outros colegas para trás, evidenciando o aspecto de selecionismo;

b) oportunidades para os alunos usarem matemática como ferramenta analítica da sociedade. Por exemplo, ser capaz de explorar e criticar certos aspectos sociais através da Matemática;

c) noções alternativas de conhecimento. Geralmente feitas através da comparação do conhecimento científico com o prático, de forma a priorizar o saber matemático (D’AMBROSIO, 2006 apud GUTIÉRREZ, 2012, p. 20);

d) repensar o campo da matemática de uma forma mais humanista. "[...] reconhecendo que a matemática precisa de pessoas, e não apenas as pessoas precisam de matemática" (GUTIÉRREZ, 2012, p. 20, tradução nossa).

Como podemos perceber, o poder se torna então o ponto crítico em todo esse sistema, que lida com diferentes níveis de transformação social. É nessa dimensão que 
estão inseridos os sujeitos que decidem o currículo matemático, que definem prioridades e manejam recursos, que decidem quem se torna marginalizado ou não, etc.

Para Gutiérrez (2012), as dimensões ainda podem ser classificadas em dois eixos, quais sejam: dominatee crítico. O eixo dominante, que consiste na união das dimensões acesso e realização, as quais a autora considera condiçõesnecessárias para que os alunosparticipem mais ativamente do contexto social em que estão inseridos. $\mathrm{O}$ eixo crítico, que compreende a união das dimensões identidade e poder, o qual é equivalente às questões críticas da Matemática que garantem referências e recursos capazes de ajudar na formação de cidadãos críticos.

A autora sumariza comentando que todas as quatro dimensões são necessárias se queremos atingir uma "equidade verdadeira", sendo necessário aos alunos aprenderem a Matemática dominante, em ordem de poderem contribuir criticamente como figuras da sociedade. A contribuição mencionada deve ser feita de modo positivo, visando erradicar as inequidades. Ademais, acredita que "Não basta aprender a jogar o jogo [da Matemática]; os alunos também devem ser capazes de mudá-lo. Mas mudar o jogo exige que sejam capazes de jogá-lo bem o suficiente para serem levados a sério" (GUTIÉRREZ, 2012, p. 21, tradução nossa).

Diante do exposto, constatamos que os pesquisadores da linha de pesquisa em equidade Matemática devem ter sempre as quatro dimensões em mente, mesmo que por vezes, alguma predomine em detrimento das demais. A autora ressalta ser importante sempre ter o discernimento de que a equidade pode se manifestar de diferentes modos, dependendo das expectativas do educador, das necessidades e do contexto em que os alunos se encontram.

\section{Equity Quantified in Participation}

A EQUIP encontra-se em fase de estudo (implementação), logo nos detemos a alguns aspectos norteadores da referida ferramenta, a partir de nossa experiência de intercâmbio. Para o seu desenvolvimento, foi primordial a elaboração de códigos que auxiliassem tanto na criação, quanto no seu aprimoramento.

O planejamento inicial da pesquisa compreendeu a ordenação das etapas, quais sejam: discussão e criação de um livro de códigos previamente adotado, com base no contexto da proposta; análise da literatura existente sobre o tema; treinamento de pessoal; codificação e coleta de dados inicial; modificação do livro de códigos 
(constantemente); codificação das vídeo aulas também já especificadas no projeto da pesquisa; processo de confiabilidade da codificação; e por último, retoques no livro de códigos.

A criação do livro de códigos, que estava previsto no projeto inicial dos autores, é assim chamado não por conter códigos em linguagem de computação, mas sim algoritmos escritos que possivelmente iriam ajudar na programação posterior do aplicativo. Para a codificação, as análises de participação dos alunos eram classificadas em dimensões, que refletiam como a aula de Matemática estava sendo guiada. Por motivos de confidencialidade, tais códigos e a maneira que estão dispostos, não podem ser compartilhados sem permissão.

Houve o momento de consulta da literatura existente sobre a medição de equidade em participações no contexto de classe de Matemática, e sobre algumas ferramentas já existentes, que chamaram atenção por medirem equidade apenas de forma quantitativa, ou qualitativa. Percebemos que a junção dessas duas formas de medidas era necessária, para que a EQUIP fosse mais eficaz. Logicamente seria a inovação do projeto, juntamente com a ambiciosa função de medição em tempo real.

A fase de treinamento da equipe foi marcada pelo uso dos primeiros códigos para análise de dois vídeos famosos entre os pesquisadores de Educação Matemática dos EUA: Sean Numbers e Number Talks. O primeiro consiste na filmagem de uma classe de Matemática de terceiro ano em Michigan, que mostra 10 minutos de uma discussão mais longa sobre números pares e ímpares. Segundo as transcrições de Ball (1990), um menino chamado Sean comenta que ele notou algo especial sobre o número seis. Ele afirma que pode ser tanto par quanto ímpar. Sean explica sua ideia, levantando outras perspectivas, contra-argumentos e questionamentos. Já o Number Talks trata-se de uma indagação da professora de Matemática sobre uma operação simples, como 38 + 37, e pede que seus alunos apontem a resposta correta, explicando a Matemática utilizada por trás de seu raciocínio, a chamada Matemática de alto nível.

Ambos os vídeos continham as atividades escritas utilizadas em sala, a transcrição de tudo que foi falado nos vídeos e as notas de aula dos professores. A missão da equipe de análise era separar os discursos de sala de aula em fragmentos menores, chamados de "sequências de participação". A primeira fase desta análise envolveu a codificação das discussões de acordo com os problemas levantados, que se transformaram em dimensões de interações em sala de aula. 
Nas reuniões, notamos que algumas dimensões não eram interessantes para o projeto, outras eram redundantes, e algumas outras foram adicionadas. As dimensões utilizadas então tratavam da divisão de participações por aluno; do tipo de discurso do estudante: matemáticos ou não matemáticos; do método de solicitação de participação: solicitada pelo professor, aleatória ou espontânea; do tempo que os alunos levavam para responder uma questão: curto, médio ou longo; do tipo de pergunta: o que, como, por que, ou outros; e como o professor respondia e reagia às ideias dos alunos.

Após intercaladas e comparadas as codificações dos membros da equipe, havendo coerência e confiabilidade tanto individualmente quanto em grupo, era chegado o momento de iniciarmos na grande etapa da decodificação de aulas que seriam o objeto de estudo. Os materiais utilizados para esta etapa foram 20 vídeos de aulas de Matemática (cerca de uma hora cada) produzidos pela equipe participante do referido projetoe desenvolvidos no Laboratório de Matemática Elementar (EML) da MSU. Assim, foram realizadas pela equipe envolvida, as transcrições, o registro dos nomes de todos os alunos participantes, o tempo minuciosamente medido e a análise qualitativa e quantitativa dos conteúdos ministrados. Por motivos de confidencialidade não divulgaremos os nomes ou quaisquer outros dados do professor e dos alunos envolvidos nos vídeos.

Uma vez atestada a confiabilidade do método, repetimos nesses 20 longos vídeos o mesmo processo utilizado em Sean Numbers e Number Talks. O diferencial desta etapa foi a comparação da codificação dos membros da equipe com a codificação dos mentores, além da recodificação de sequências de participação de modo aleatório. As discrepâncias encontradas eram discutidas e analisadas mais calmamente nas constantes reuniões feitas.

Ao final de três meses e todo o processo realizado, tínhamos atestado a capacidade e eficiência dos códigos para gerarem resultados preliminares sobre medição de equidade em participações. Os códigos foram mais uma vez verificados e potencializados para uma adequação e facilitação de compreensão dos futuros usuários. O desenvolvimento desse livro de códigos será útil para dar prosseguimento à pesquisa, e servirá como base para a criação e divulgação da ferramenta EQUIP. 


\section{Distribuição da aprendizagem de forma equitativa entre os mais diversificados perfis dos alunos nas aulas de matemática: análise preliminar dos vídeos produzidos}

De forma generalista, nãopodemos afirmar que todos os alunos estão participando de uma forma cognitivamente favorável. Porém, nos cabe permitir que as oportunidades estejam ao alcance dos mais variados grupos que podemos encontrar numa sala de aula, partindo do pressuposto que a maioria das turmas apresentam alunos de diversificadas etnias, classes sociais, sexo, cultura, religião, etc.

Dado o papel importante que a Matemática desempenha na formação acadêmica e profissional de cada indivíduo, aceitamos os conceitos de Gutiérrez (2002) sobre equidade, no que diz respeito ao envolvimento dos alunos com a "matemática crítica", referindo-se ao fato de os alunos desenvolverem a capacidade de usar a Matemática para analisar criticamente as forças sociohistóricas e institucionais de maneira a fazer que a Matemática necessariamente assuma questões sociais e políticas, destacando especialmente as perspectivas dos grupos marginalizados.

De modo mais amplo, Gutiérrez (2002, p. 166) elucida uma "relação positiva entre Matemática, pessoas e o planeta de forma a apagar as inequidades" como modo de impulsionar as participações e de questionar a sociedade através de práticas Matemáticas. Ademais, para a autora, uma sala de aula equitativa proporciona a todos os alunos uma oportunidade igual de participação nas práticas disciplinares constitutivas do processo de aprendizagem, como compartilhar ideias, fazer perguntas, justificar o raciocínio e engajar em interações.

Para tanto, nossa análise parte de alguns questionamentos balizadosa partir dos dados iniciais obtidos através da decodificação dos vídeos na fase inicial do projeto EQUIP, juntamente com dados mais globais, de maneira a construirmos um entendimento entre o objeto de estudo e a literatura na área.

Quem tem a vez na participação em discussões de sala de aula? Naturalmente, todos os envolvidos no processo de construção cognitiva devem ter a chance de participar, opinar, responder ou mesmo discordar. Porém, haverá sujeito com propensão a participar mais ou menos no contexto de sala de aula. O Gráfico 1 ilustra o exemplo de participação dos 30 alunos dos 20 vídeos do EML. 

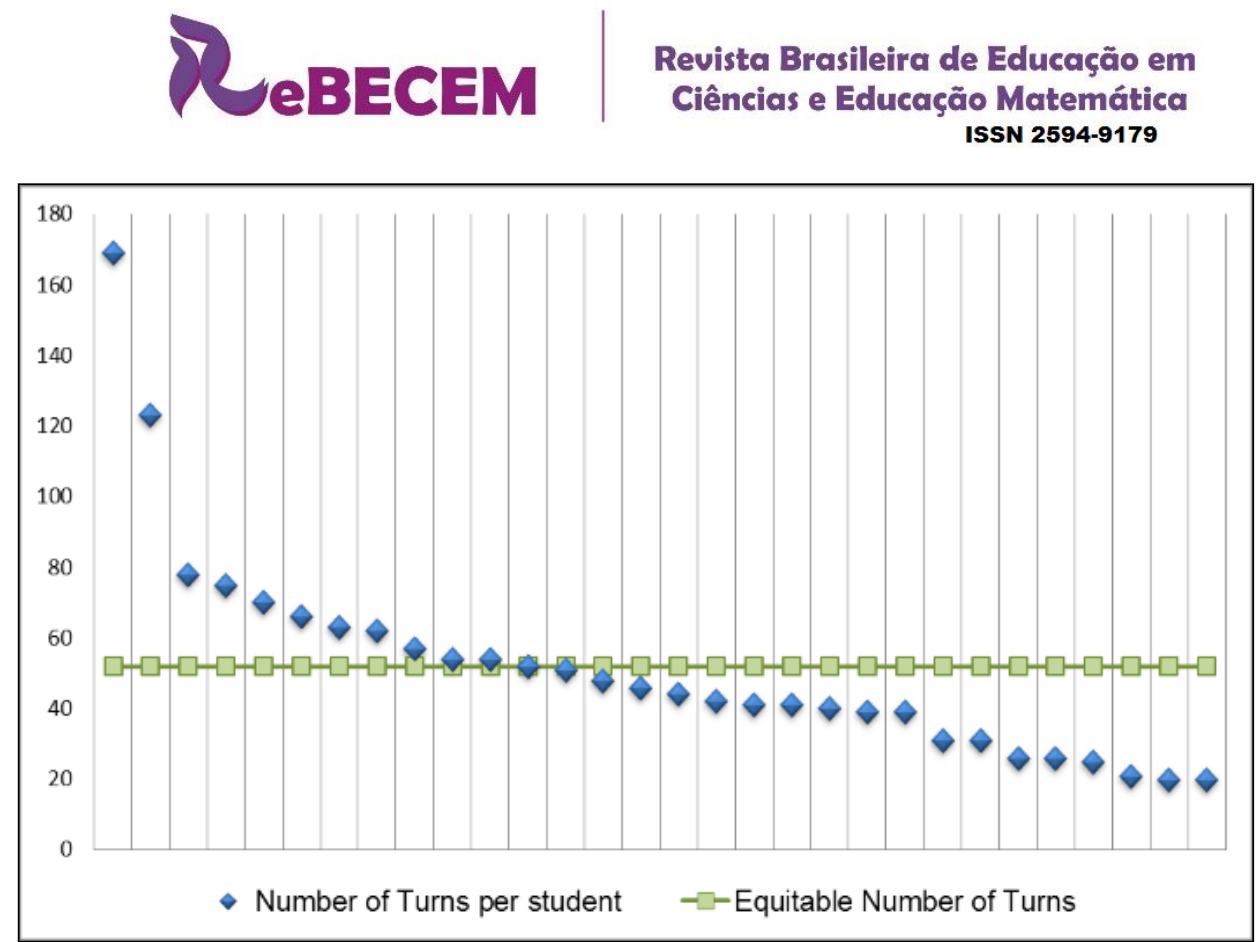

Gráfico 1: Distribuição de participação por alunos

Fonte: Dados da pesquisa

Notamos que há alunos que se sobressaem nas participações e podemos destacar, no comportamento da maioria da turma envolvida, que mais da metade desta está abaixo do número de participações equitativas adequada para uma sala de 30 alunos. Afora que observamos dois alunos com participações muito acima da média.

Ao tomarmos a classe como um todo, e novamente dividirmos, porém desta vez por gênero, obtivemos o resultado ilustrado no Gráfico 2. No referido gráfico, podemos perceber que a quantidade de meninos e meninas é igual, logo a distribuição equitativa mais justa seria de $50 \%$, porém o número de participações dos meninos se mostra bem acima do ideal.

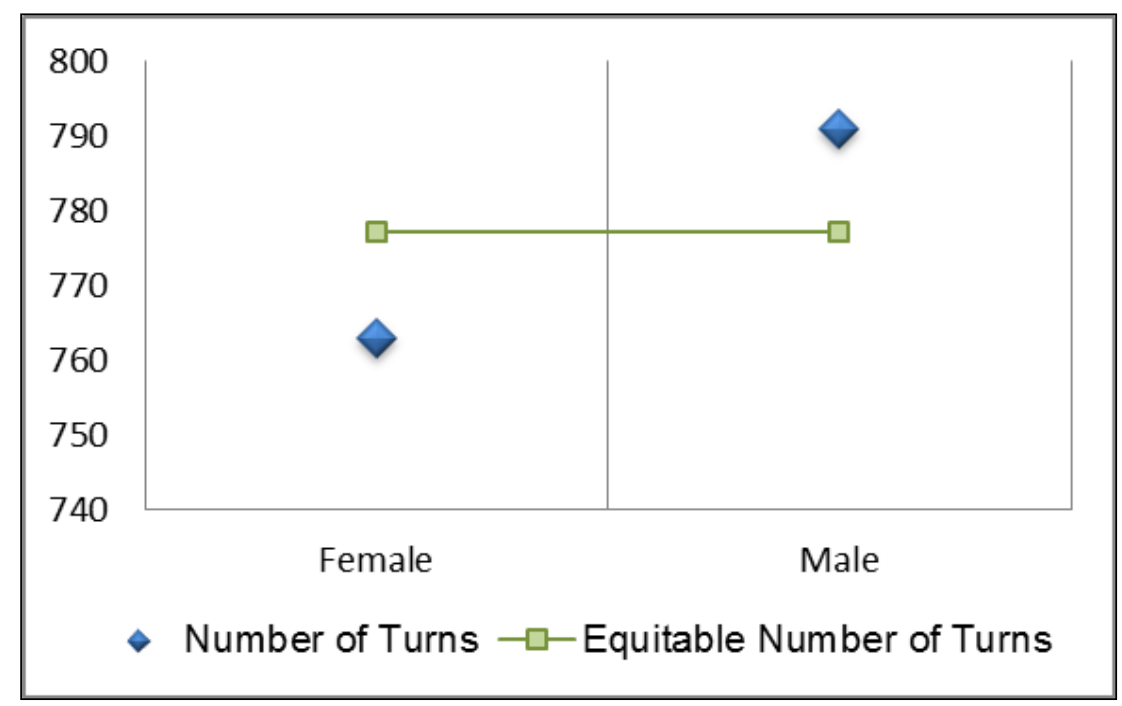

Gráfico 2: Distribuição de participação por gênero

Fonte: Dados da pesquisa 
Já no Gráfico 3, observamos a distribuição de participação por etnias. Vale atentar que, por se tratar de uma pesquisa no âmbito norte-americano, foi-se levado em consideração o papel dessas três principais etnias destacadas: afrodescendentes, latinos e brancos. Outras etnias não foram documentadas nas transcrições orais dos vídeos. Outrossim, as próprias crianças que autodenominaram suas respectivas etnias, deixando bem claro que não foi usado nenhuma suposição ou premissa que poderia ser classificada como racista.

O Gráfico 3 ilustra claramente que durante a pesquisa de elaboração da EQUIP, a maioria dos alunos investigados se identificavam com a cor da pele negra. Vale ressaltarmos que os alunos participantes desta pesquisa foram convidados de UrbanSchools $^{4}$ da região de Michigan. O que é possível observarmos no gráfico é a exata participação de alunos considerados brancos equitativamente. Porém, os dados não demonstram nivelamento no que diz respeito a alunos negros e latinos.

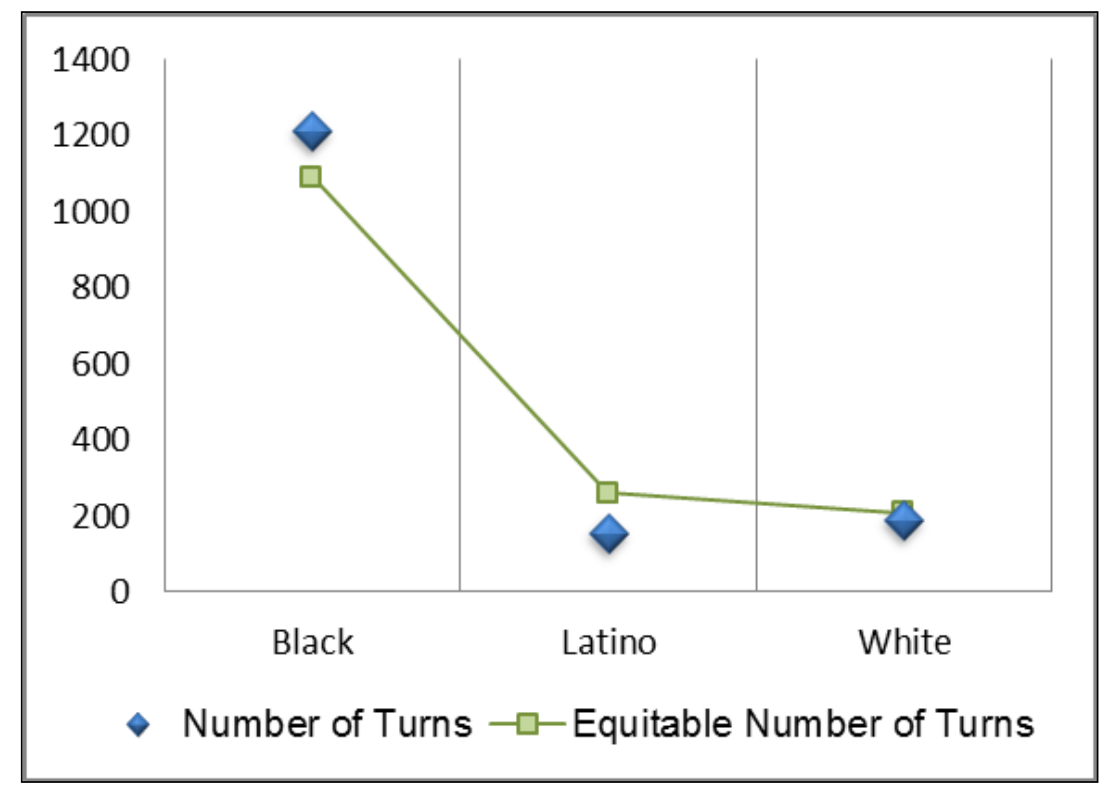

Gráfico 2: Distribuição de participação por etnias Fonte: Dados da pesquisa

Qual é a natureza dessas participações?Quando os alunos participam da aula, houve momentos específicos? À guisa de identificação, às vezes participaram da construção do conhecimento, outrasindagaram sobre assuntos não correspondentes com a disciplina, ou apenas conversando paralelamente. Houve momentos em que o professor solicitou a participação dos alunos, outros momentos os próprios

\footnotetext{
${ }^{4}$ UrbanSchools são escolas que atentem em áreas urbanas das cidades norte-americanas, geralmente com alunos provenientes de classe média ou baixa, possivelmente com altas taxas de pobreza, população diversificada e multicultural, com altas taxas de alunos cuja língua materna não é o inglês.
} 
alunosengajaram-se em interações em conjunto com a turma, ou apenas com o professor.

O Gráfico 4 apresenta o envolvimento dos alunos com o conteúdo matemático ou logístico, propriamente dividido de acordo com o gênero e etnia.

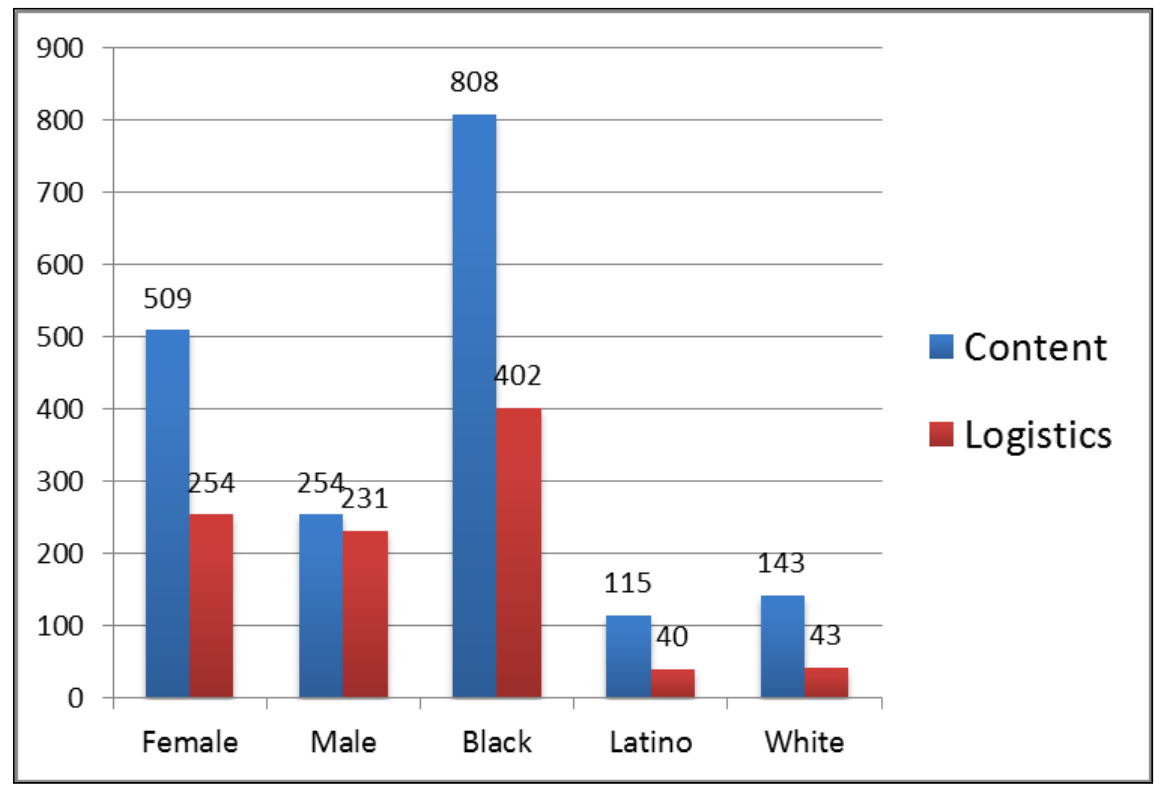

Gráfico 3: $\mathrm{N}^{\mathrm{o}}$ de interações dos alunos com o conteúdo matemático de acordo com gênero e etnia Fonte: Dados da pesquisa

Comparando o Gráfico 2 com o Gráfico 4, percebemos que mesmo as meninas tendo uma distribuição de participação menor, elas geralmente discutiam mais sobre o conteúdo do que os meninos, o que teoricamente nos ajuda a repensar máximas a respeito do gênero masculino na Matemática. No caso da natureza das participações dividida por etnias, percebemos que o conteúdo geralmente estaria sendo mais discutido do que assuntos de logística.

Como as diferentes formas de participação são distribuídas pelos alunos na turma? Para podermos elucidar sobre este questionamento, devemos remeter a que aspecto de equidade estamos levando em conta nas nossas análises. No âmbito da construção da ferramenta EQUIP, e, levando em consideração os grupos raciais estudados, podemos verificar que todos participaram de forma mais ou menos equilibrada, porém se estivermos interessados na quantidade de tempo que os alunos demoram para responder, ou na quantidade de palavras utilizadas na resposta, isso nos possibilitaria uma nova perspectiva a ser estudada.

Todavia, ao nos atermos ao binômio "participou ou não", podemos observar nos gráficos supracitados, que os alunos negros do sexo masculino participavam mais 
ativamente das aulas de Matemática, porém alunas negras do sexo feminino estavam mais engajadas nas atividades. Olhando para as inequidades, observamos que alunos latinos, mesmo estando em quantidade maior que os alunos brancos, obtiveram uma menor participação nas aulas. Neste último caso, a medida da proficiência na língua em que a aula é ministrada se faz necessária, uma vez que um país como os Estados Unidos não possui um idioma oficial designado.

\section{Colocando em perspectiva: proposição de ações metodológicas através das dimensões de equidade nas aulas de Matemática}

Ao extrairmos dos gráficos ilustrados alguns padrões relacionados à equidade, nos deparamos com a possibilidade de capturar quantitativamente a essência das salas de aula, o que pode facilitar investigações sistemáticas de equidade, levando a possíveis

resultados mais justos. A Figura 1 apresenta um esquema de proposição de ações metodológicas através das dimensões de equidade nas aulas de Matemática.

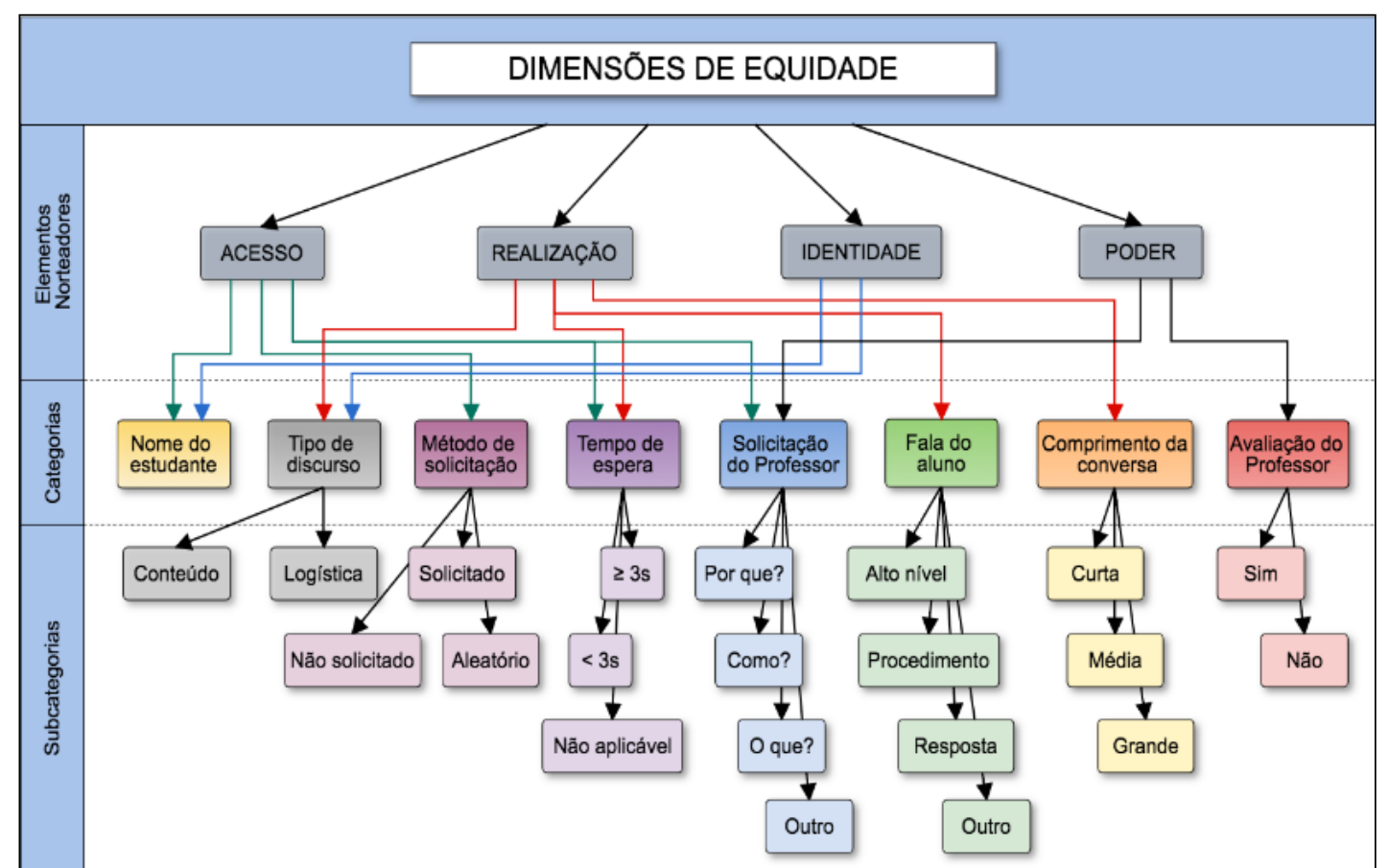

Figura 1: Esquema de proposição de ações metodológicas através das dimensões de equidade nas aulas de Matemática

Fonte: Elaborada pelos autores

De forma explícita segue os desdobramentos de uma proposta de roteiro metodológico através das dimensões de equidade nas aulas de Matemática. Tomando os elementos norteadores como ponto de partida, temos: 
1. NOME DO ESTUDANTE (Uma sequência de participação é enunciada quando um aluno contribui para a discussão em sala de aula. Deve-se tomar nota desta sequência utilizando o nome do estudante. Uma nova sequência é formada quando o estudante é substituído do diálogo, ocasionando em uma nova interação.) - [1.1] Conhecer os nomes dos seus alunos é essencial para identificar quem está participando de possíveis sequências. [1.2] Tentar tomar nota de quantas vezes cada aluno está participando da aula, isso ajudará a manter o balanço, uma vez que forem analisados os dados coletados. [1.3] Interrupções, conversas paralelas ou participações em grupo não devem ser contadas como sequências de participação. [1.4] Esta categoria se relaciona rigorosamente com a dimensão de equidade identidade, uma vez que o professor reconhece o aluno como sujeito, acarretando na utilização de premissas de identidade. Também se pode dizer que esta é a primeira instância para o acesso a recursos pedagógicos.

2. TIPO DE DISCURSO (Trata-se da distinção da sequência de participação em Matemática, ou apenas logística de sala de aula ou conversas paralelas.) - [2.1] Pode ser subdividido em duas partes: CONTEÚDO: qualquer interação que envolva a Matemática, perguntas, respostas ou debate. LOGÍSTICA: conversas relacionadas com a logística de sala de aula, ou mesmo qualquer outro assunto não relacionado com o conteúdo. [2.2] Por tratar de instâncias as quais as sequencias estão inseridas, temos que esta categoria apela para a dimensão realização, uma vez que aborda a participação efetiva no conteúdo. Ademais, como a resposta depende diretamente do conhecimento do discente, é assertivo afirmar que a dimensão identidade também é norteadora.

3. MÉTODO DE SOLICITAÇÃO (Refere-se ao engajamento de participação do aluno, solicitado ou não pelo professor.) - [3.1] Pode ser subdividido em três partes: SOLICITADO: quando o professor chama o aluno pelo nome, ou quando de alguma forma o engaja na participação. NÃO SOLICITADO: quando o estudante participa sem a solicitação ou permissão do professor. ALEATÓRIO: quando o aluno que participa é escolhido de forma aleatória. [3.2] Alunos que respondem perguntas de outros alunos, mesmo fazendo parte do diálogo do conteúdo, devem ser avaliados como "não solicitado". [3.3] Esta categoria explicitamente trata do acesso ao conteúdo.

4. TEMPO DE ESPERA (Se ocupa com o tempo desde o final da solicitação inicial do professor até o momento que um aluno é escolhido para participar.) - [4.1] Por se tratar de uma dimensão que mede a rapidez do raciocínio do aluno em contrapartida com a solicitação do professor, podemos considerar para nossas análises 
intervalos: maiores ou iguais a 3 segundos, menores que 3 segundos, ou não aplicável: $\geq$ 3: tempo entre a pergunta ou solicitação do professor até a escolha do aluno maior ou igual a 3 segundos. < 3: tempo menor que 3 segundos. NÃO APLICÁVEL: quando o método de solicitação for "não solicitado"; quando não houve solicitação por parte do professor; quando a pergunta parte de um estudante a outro. [4.2] Solicitações em que se repete o estudante anterior não precisam ser levadas em consideração. [4.3] O acesso é fator norteador desta categoria, pois a dinâmica de sala garantirá os que participaram e em que ordem. A realização também é fator influente, já que consideramos a participação efetiva do aluno.

5. SOLICITAÇÃO DO PROFESSOR (Corresponde às indagações do professor que iniciam uma nova sequência de participação.) - [5.1] Podemos classificar essa categoria em: POR QUE: uma solicitação que exige do aluno uma explicação e/ou justificativa da Matemática utilizada por trás da resposta. COMO: uma solicitação que exige do aluno o relato dos passos utilizados na resolução do problema, ou apresente os procedimentos. O QUE: uma solicitação que exige uma resposta verbal ou numérica curta, que leia um problema, ou relate um fato. OUTRO: uma solicitação que não necessariamente tenha relação com o conteúdo; uma solicitação de resposta em grupo (por exemplo, “todos entenderam?”); no geral, solicitações não matemáticas. [5.2] O acesso também influencia diretamente esta categoria, porém a dimensão de poder tem específica participação, de maneira que o professor quem define as prioridades de acesso e participação.

6. FALA DO ALUNO (Resposta à solicitação do professor.) - [6.1] Pode ser subdividido em quatro esferas: ALTO NÍVEL: o estudante explica ou justifica a Matemática utilizada na sua resposta. Geralmente trata-se de explicação utilizando um ou mais conceitos matemáticos. PROCEDIMENTO: o aluno apresenta os passos utilizados que o permitiram chegar a resposta. Geralmente ele utiliza uma fórmula ou passo-a-passo memorizado na aula ou pesquisado anteriormente. RESPOSTA: trata-se da resposta verbal ou numérica de um problema, leitura do enunciado de algum exercício ou qualquer resposta sobre o conteúdo sem devida explicação ou profundidade. OUTRO: indagações de um estudante a outro, ou mesmo ao professor, mas que não tenham relação com o conteúdo. [6.2] A "Solicitação do Professor" e a "Fala do Aluno" se correlacionam. [6.3] Trata-se da realização do aluno, ao conseguir engajar corretamente na solicitação feita pelo educador. 
7. COMPRIMENTO DA CONVERSA (Refere-se à quantidade de palavras em uma única expressão contínua por parte do aluno durante a interação com o professor e/ou com outros alunos.) - [7.1] Pode ser subdividido em três partes: CURTA: geralmente quando a resposta do aluno tem entre 1 e 4 palavras. MÉDIA: de 5 a 20 palavras. GRANDE: mais de 20 palavras. [7.2] Indica-se usar do bom senso quando se estiver analisando esta seção. Há facilidade quando se está observando gravações de aulas ou conversas transcritas. [7.3] O debate entre o professor e um único estudante, por ser uma só sequência de participação, no caso em que o aluno responde com 1 palavra, depois com 5, depois com 20, considera-se como "grande". [7.4] Em momentos que o estudante é interrompido (pelo professor ou por conversas paralelas), mas o raciocínio do seu questionamento segue, considera-se como ainda sendo a mesma participação. [7.5] Respostas numéricas, como por exemplo, "cinquenta e dois", pode ser considerado como uma única palavra. [7.6] A especificidade desta categoria é completada pela dimensão de realização, por aludir uma participação (mais ou menos) efetiva no conteúdo.

8. AVALIAÇÃO DO PROFESSOR (Trata-se da avaliação explícita do professor por uma ou mais ideias dos alunos, isto é, de momentos em que o professor faz uma afirmação positiva, crítica ou elogio ao que o aluno diz.) - [8.1] Pode ser classificada como avaliação do professor: Sim ou Não. SIM: quando há um claro exemplo de avaliação: quando o professor faz uma crítica ou elogia tal interação, mesmo ela não estando necessariamente correta. NÃO: quando a avaliação não é explícita, ou quando não há feedback algum do professor para o aluno. [8.2] A dimensão de equidade poder norteia esta categoria, uma vez que o professor, como autoridade maior em sala de aula, é responsável pela escolha de prioridades, o que impulsiona o ensino.

Para potencializar a aplicação do roteiro metodológico acima sugerido, destacamos a relevância da elaboração de uma proposta de ficha investigativa que possa auxiliar os professores e pesquisadores interessados em conhecer os níveis de equidade em salas de aulas de Matemática. Sua apropriação deve compreender uma coleta de dados em sala de aula, de modo a orientar os professores a reconhecerem quais os alunos estão participando, qual a natureza implícita dessa participação e como o conteúdo pode estar sendo distribuído entre a turma. 


\section{Considerações}

Nesta pesquisa descrevemos o funcionamento de uma ferramenta de quantificação de participações equitativas nas aulas de Matemática, fruto de um projeto de pesquisa que terá como resultado a criação de um aplicativo capaz de auxiliar professores e pesquisadores no campo educacional da Matemática, a fim de auxiliar na distribuição justa e equitativa do conhecimento matemático nas salas de aula.

Outrossim, ao analisarmos sobre a distribuição equitativa de uma amostra americanaquanto aos diversos perfis de alunos nas aulas de Matemática, percebemos a necessidade de dados mais sólidos e concisos que possam corroborar com a realidade do sistema de ensino em questão. À guisa de exemplificação, observamos a necessidade da exploração de dados que envolvam a qualidade do ensino de Matemática entre pessoas de baixa renda, de etnias variadas, de necessidades especiais, de gênero, entre outras.

Portanto, para que haja a ampliação desse objeto de estudo, depreendemos a necessidade de pesquisa constante sobre a equidade nas aulas de Matemática desde a sensibilização sobre os problemas de distribuição de participação até as potencialidades metodológicas necessárias para a promoção de um ambiente mais justo e equitativo no que diz respeito ao processo de ensino e aprendizagem da Matemática.

Contudo, apresentamos um esquema de proposição de ações metodológicas através das dimensões de equidade nas aulas de Matemática, que tem o intuito de auxiliar nas pesquisas e práticas matemáticas. Ademais, no âmbito brasileiro, recomendamos trabalhos futuros, desde o estudo das questões de equidade da Base Nacional Comum Curricular até o estudo dos dados do Sistema Nacional de Avaliação da Educação Básica interpretados com base nas relações de equidade.

\section{Referências}

ANDREWS, D. J. C. Black achievers' experiences with racial spotlighting and ignoring in a predominantly White high school. Teachers College Record, New York, v. 114, n. 10, p. 1-46, 2012.

BALL, D. L. Sean numbers: transcript from Deborah Ball's classroom, January 19, 1990. East Lansing, Michigan: MATH Project, College of Education, Michigan State University. Used with permission, 1990. Disponível em: 〈http://hdl.handle.net/2027.42/65013>. Acesso em: 01 aug. 2017.

BOALER, J. Promoting 'relational equity' and high mathematics achievement through an innovative mixed- ability approach. British Educational Research Journal, Oxfordshire, v. 34, n. 2, p. 167-194, 2008. 
D'AMBROSIO, U. Etnomatemática - elo entre as tradições e a modernidade. 2. ed. Belo Horizonte: Autêntica, 2005.

D'AMBROSIO, U. Ethnomathematics: link between traditions and modernity. Rotterdam: Sense Publishers, 2006.

ELLINGTON, R. E.; PRIME, G. Reconceptualizing quality and equity in the cultivation of minority scholars in mathematics education. In: ATWEH, B. et al. (Eds.). Mapping Equity and Quality in Mathematics Education. Dordrecht: Springer, 2011. p. 423-435.

FARIA, E. M.; GUIMARÃES, R. R. M. Excelência com equidade: fatores escolares para o sucesso educacional em circunstâncias desfavoráveis. Estudos em Avaliação Educacional, São Paulo, v. 26, n. 61, p. 192-215, 2015.

FRANCO, C. et al. Qualidade e eqüidade em educação: reconsiderando o significado de "fatores intra-escolares". Ensaio: avaliação e políticas públicas em educação, Rio de Janeiro, v. 15, n. $55,2007$.

GUTIÉRREZ, R. Enabling the practice of mathematics teachers in context: toward a new equity research agenda. Mathematical Thinking and Learning, Londres, v. 4, n. 2-3, p. 145-187, 2002.

GUTIÉRREZ, R. A “gap-gazing” fetish in mathematics education?: problematizing research on the achievement gap. Journal for Research in Mathematics Education, Reston, v. 39, n. 4, p. 356-364, 2008.

GUTIÉRREZ, R. Context matters: how should we conceptualize equity in mathematics education? In: EISENMANN, B. H. et al. (Eds.). Equity in discourse for mathematics education. Dordrecht: Springer, 2012. p. 17-33.

HITT, M. A. Comportamento organizacional: uma abordagem estratégica. Tradução de Teresa Cristina P. de Souza. Rio de Janeiro: LTC, 2007.

LUBIENSKI, S. T. On "gap gazing" in mathematics education: the need for gaps analyses. Journal for Research in Mathematics Education, Reston, n. 39, p. 350-356, 2008.

MANTOAN, M. T. E. Ensinando a turma toda: as diferenças na escola. In: MANTOAN, M. T. E. (Org.). O desafio das diferenças nas escolas. 4. ed. Rio de Janeiro: Vozes, 2011.

MICHAELIS. Moderno Dicionário da Língua Portuguesa. Editora Melhoramentos, 2015.

Disponível em: <http://michaelis.uol.com.br/moderno-portugues/>. Acesso em: 18 jun. 2017.

MOSES, R. P.; COBB, C. E. Radical equations: math literacy and civil rights. Boston: Beacon Press, 2001.

SECADA, W. G. Social and critical dimensions for equity in mathematics education. In: SECADA, W. G. (Org.). New directions for equity in mathematics education. New York: Cambridge University Press, 1995.

SILVA, G. H. G. da. Equidade e educação matemática. Educação Matemática Pesquisa, São Paulo, v. 18, n. 1, p. 397-420, 2016. 
SUN, A. Equality is not enough: what the classroom has taught me about justice. Everyday Feminism, 2014. Disponível em: <http://everydayfeminism.com/2014/09/equality-is-notenough/>. Acesso em: 18 june. 2017.

WAGER, A. A. Noticing children's participation: insights into teacher positionality toward equitable mathematics pedagogy. Journal for Research in Mathematics Education, Reston, v. 45 , n. 3, p. 312-350, 2014.

Recebido em: 17 de outubro de 2018.

Aceito em: 14 de dezembro de 2018. 